\title{
Uranium Concentrations measurement for Ground Water and Soil Samples in Al-Najaf/Iraq
}

\author{
Ali A. Abojassim \\ Department of Physics $\backslash$ College of Science $\backslash$ University of Kufa PO box (221) Najaf, Iraq,
}

\begin{abstract}
In this work, Uranium concentrations in groundwater and soil samples from some areas of Al-Najaf city, Iraq were measured solid state nuclear track detector (CR-39) detector technique. The uranium

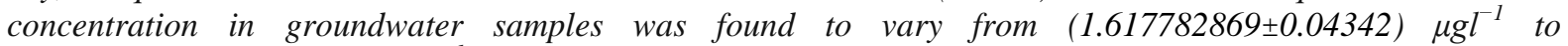
$(5.079235843 \pm 0.137827) \mu g l^{-1}$, while in soil samples vary from $(0.093558 \pm 0.000938)$ ppm to $(0.184325 \pm 0.017511) \mathrm{ppm}$.
\end{abstract}

This study showed that levels of uranium concentration in groundwater and soil of study area of were compared with safe limit values recommended by WHO and UNSCEAR below the safe limit .

Keyword: Uranium Concentrations in groundwater, Uranium Concentrations in soil, Najaf Holy city

\section{Introduction:}

Natural radiation has always been part of the human environment. Its main components are cosmic and cosmogenic radiation, terrestrial gamma radiation from natural radionuclides in rocks and soil, and natural radioactive substances in our diet and in the air we breathe[1] .

Radionuclides are found in the environment as naturally occurring elements and as products or byproducts of nuclear technologies, one of the most common radionuclides is uranium (U), all isotopes of uranium are radioactive, so it is very important their quantity to be under control [2].

Uranium is a silvery-white metallic chemical element in the actinide series of the periodic table, with symbol $\mathrm{U}$ and atomic number 92. A uranium atom has 92 protons and 92 electrons, of which 6 are valence electrons. Uranium is weakly radioactive because all its isotopes are unstable. The most common isotopes of uranium are uranium-238 (which has 146 neutrons) and uranium-235 (which has 143 neutrons). Uranium has the second highest atomic weight of the primordially occurring elements, lighter only than plutonium [3].

Uranium is present almost in all soils, rocks and waters. Water passing through and over rock and soil formations dissolves many compounds and minerals, including uranium, so varying amounts of it are present in some water sources.

There are some scientists modernly using track detector to measure uranium of concentration for water and soil. N. H. Kadhim and et al. in (2011)[4] studied the measurement of uranium concentrations in 25 soil samples from five locations of Al-Kut city using SSNTDs technique. N. H. Kadhim and et al. in(2012) [5] studied to measure the concentrations of uranium for (20) soil samples covering (4) areas in Baghdad with different depths (10-20-30-40-50) $\mathrm{cm}$, The concentrations were estimated by using the technique of counting the fission fragments in (CR-39) detector resulting from the fission of nuclei ${ }^{235} \mathrm{U}$. And K. Brindha and L. Elango in (2013) [6] studied for Occurrence of uranium in groundwater of a shallow granitic aquifer and its suitability for domestic use in southern India. The structure of this study was determined the important radioactive element that it is called radon in healthy drinking water, because several factors such as Increase the use and availability in markets of different types.

\section{Area of Study:}

Najaf is located on the edge of western plateau of Iraq, at southwest of Baghdad the capital city of Iraq, at $160 \mathrm{~km}$ far from the capital. It is 70 meters above sea level and is situated on longitude of 19 degree and 44 minutes, latitude of 31 degree and 59 minutes [7]. It is boarded from north and northwest by Karbalaa city (which is $80 \mathrm{~km}$ far from it), and from the south and west by low sea of Najaf, and Abi Sukhair (which is $18 \mathrm{~km}$ far from the city) and from the east by Al- Kufa city (which is $10 \mathrm{~km}$ far from the city)[8].

In the present study (10) regions were chosen as fair distribution in Al-Najaf and Al-Kufa cities. The regions were determined using (GIS) as shown in Fig.(1) that Al-Najaf city. Table (1) showed the sites of measurement in studied area for taking samples. 


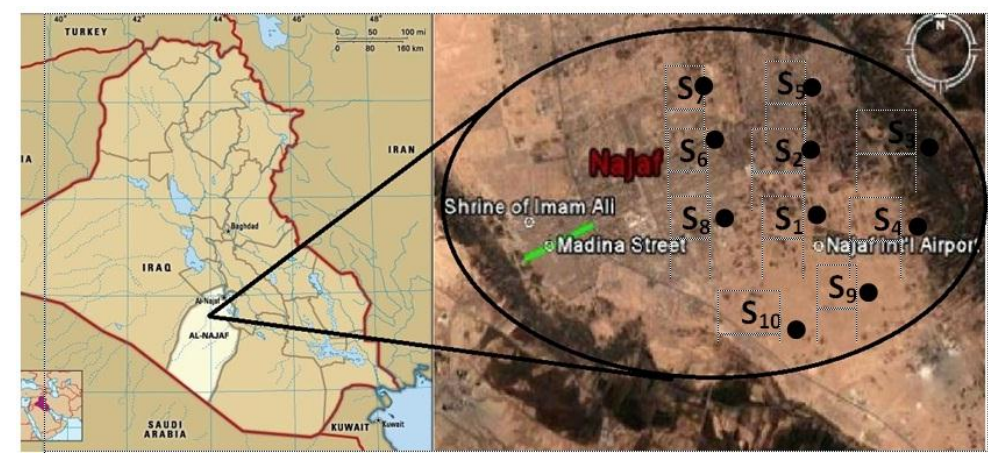

Fig.(1): Map of Al-Najaf city

Table (1): The sites of measurement in studied area for taking samples

\begin{tabular}{|c|c|c|c|}
\hline No. & Location name & Sample & Coordinates \\
\hline 1 & Al.Motanaby & $\mathrm{S} 1$ & $44^{0} 22^{\prime} 53.662^{\prime \prime} \mathrm{E}, 32^{0} 1^{\prime} 48.533^{\prime \prime} \mathrm{N}$ \\
\hline 2 & Al.Askary & $\mathrm{S} 2$ & $44^{0} 22^{\prime} 52.701^{\prime \prime} \mathrm{E}, 3202^{\prime} 7.472^{\prime \prime} \mathrm{N}$ \\
\hline 3 & Al.Jamhoriaa & $\mathrm{S} 3$ & $44^{0} 23^{\prime} 57.168^{\prime \prime} \mathrm{E}, 32^{0} 1^{\prime} 59.881^{\prime \prime} \mathrm{N}$ \\
\hline 4 & Al.Shoarah & $\mathrm{S} 4$ & $44^{0} 23^{\prime} 21.377^{\prime \prime} \mathrm{E}, 32^{0} 1^{\prime} 40.2^{\prime \prime} \mathrm{N}$ \\
\hline 5 & Messan & $\mathrm{S} 5$ & $44^{0} 21^{\prime} 32.478^{\prime /} \mathrm{E}, 32^{0} 3^{\prime} 16.807^{\prime \prime}$ \\
\hline 6 & Al.Wafaa & $\mathrm{S} 6$ & $44^{0} 20^{\prime} 51.423^{\prime \prime} \mathrm{E}, 32^{0} 2^{\prime} 52.177^{\prime \prime} \mathrm{N}$ \\
\hline 7 & Al.Jazera & $\mathrm{S} 7$ & $44^{0} 19^{\prime} 59.966^{\prime \prime} \mathrm{E}, 32^{0} 2^{\prime} 52.596^{\prime \prime} \mathrm{N}$ \\
\hline 8 & Al.Ameer & $\mathrm{S} 8$ & $44^{0} 21^{\prime} 52.161^{\prime \prime} \mathrm{E}, 32^{0} 00^{\prime} 32.683^{\prime \prime} \mathrm{N}$ \\
\hline 9 & Al.Adala & $\mathrm{S} 9$ & $44^{0} 21^{\prime} 30.821^{\prime \prime} \mathrm{E}, 32^{0} 1^{\prime} 18.069^{\prime /} \mathrm{N}$ \\
\hline 10 & Al.Moalmen & $\mathrm{S} 10$ & $44^{0} 20^{\prime} 23.281^{\prime \prime} \mathrm{E}, 31^{0} 59^{\prime} 30.868^{\prime \prime} \mathrm{N}$ \\
\hline
\end{tabular}

\section{Experimental techniques}

uranium dosimeter techniques were used and long period in groundwater and soil samples measurements, the measurements were made with the solid state nuclear track detector (SSNTD) technique. a schematic diagram was shown in Fig.(2). Each cup container was $19 \mathrm{~cm}$ height and $7 \mathrm{~cm}$ in diameter and contains $(1 \times 1)$ $\mathrm{cm}$ square of CR-39 nuclear track detector fixed with double sided adhesive tape to the bottom of the cup with its sensitive side upward. The design of the chamber measures that the aerosol particles and radon decay products are deposited from outside. The CR-39 detectors were capable of detecting alpha particles of all energies emitted from radon and its daughters. Some of alpha particles reach the detector and leave tracks, and the number of tracks is proportional to the average radon concentration. The exposed detectors were collected after approximately five months of exposure and then chemical etching simultaneously at a constant time 7 hour and $\mathrm{NaOH}$ for $6.25 \mathrm{~N}$ at temperature $70^{\circ} \mathrm{C}$. An optical microscope with magnification of $10 \times 40$ was used to count the number of tracks in each detector.

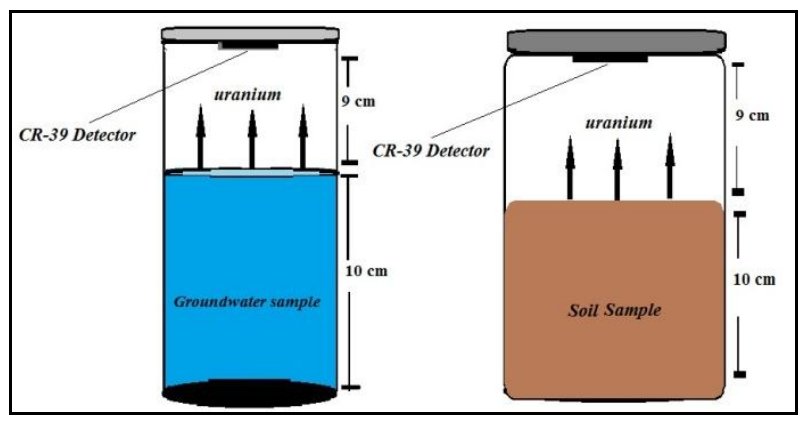

Fig.(2) A schematic diagram of the sealed-cup technique for groundwater and soil samples.

Uranium concentration in the groundwater and soil samples was measured by comparison between track densities recorded on the detectors around the samples pellets and that of the standard geological sample pellets from the relation [9] :

$$
\begin{aligned}
& \frac{C_{X}}{C_{S}}=\frac{T_{X}}{T_{S}} \\
& C_{X}=\left(\frac{C_{S}}{T_{S}}\right) \cdot \mathrm{T}_{\mathrm{X}}
\end{aligned}
$$

Where : Slope $=\left(\frac{C_{S}}{T_{S}}\right)$ 
$\mathrm{C}_{\mathrm{x}}$ : The uranium concentration in unknown sample, $\mathrm{C}_{\mathrm{S}}$ : The uranium concentration in standard sample, $\mathrm{T}_{\mathrm{x}}$ : Track density in unknown sample and $\mathrm{T}_{\mathrm{S}}$ : Track density in standard sample.

Fig. (3) and Fig.(4) show the relation between track density and uranium concentration $\left(\mu \mathrm{g} .1^{-1}\right),(\mathrm{ppm})$ for standard geological samples in groundwater and soil respectively using (CR-39) track detector.

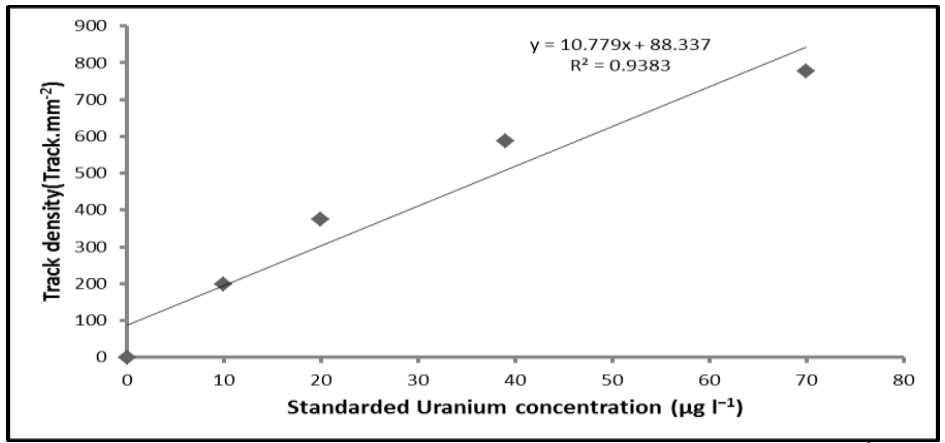

Fig.(3) The relation between track density and uranium concentration $\left(\mu \mathrm{g} . \mathrm{l}^{-1}\right)$ for standard geological groundwater samples using (CR-39) track detector.[10]

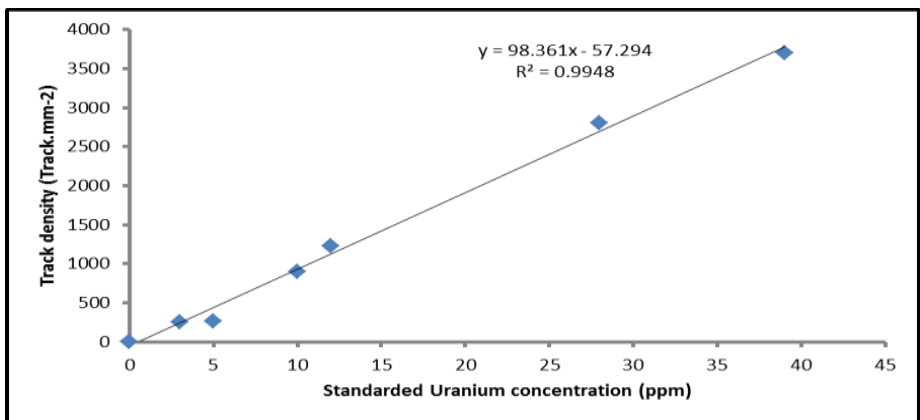

Fig.(4) The relation between track density and uranium concentration (ppm) for standard geological soil samples using (CR-39) track detector.[10]

\section{Result and Discussion:}

Table (2) and Figure (5) show the Uranium concentrations in groundwater, it includes locations, track density in $\left(\right.$ track $\left./ \mathrm{mm}^{2}\right)$ for different study areas in unit $\left(\mu \mathrm{gl}^{-1}\right)$. Table (3) and Figure (6) show the Uranium concentrations in soil, it includes locations, track density in $\left(\right.$ track $\left./ \mathrm{mm}^{2}\right)$ for different study areas in unit (ppm).

Uranium concentrations in groundwater were ranged from $(1.617782869 \pm 0.03) \mu \mathrm{gl}^{-1}$ in $(\mathrm{S} 10)$ sample to (5.079235843 \pm 0.137827$) \mathrm{\mu gl}^{-1}$ in (S5) sample, while in soil from $(0.093558 \pm 0.000938) \mathrm{ppm}$ in (S10) sample to $(0.184325 \pm 0.017511) \mathrm{ppm}$ in (S8) sample. The total average of uranium concentrations were in groundwater (3.07665586) $\mathrm{\mu g}^{-1}$ and in soil (0.153912)ppm, all the high concentrations were found at the soil surface as showing in Table(3), this is because that the radioactive content is laying on the surface of the soil and effecting by irrigation and rain fall the radioactive nucleus run away to the depths. The uranium content in soils samples are less than the allowed limit (11.7 ppm) from UNSCEAR [11] while in groundwater samples were found to have uranium concentration below the safe limit of $15 \mu \mathrm{g}$ according to WHO [12].

Table(2) Uranium concentrations in groundwater samples of Al-Najaf holy city

\begin{tabular}{|c|c|c|c|}
\hline No. & Code sample & $\begin{array}{c}\text { Track density } \\
\left(\text { Track.mm }^{-2}\right)\end{array}$ & $\begin{array}{c}\text { Uranium concentration } \\
\left(\mu \mathrm{g}{ }^{-1}\right)\end{array}$ \\
\hline 1 & S1 & 2103.239 & $2.509858174 \pm 0.089638$ \\
\hline 2 & S2 & 2653.687 & $3.166723914 \pm 0.079276$ \\
\hline 3 & S3 & 3803.858 & $4.539257784 \pm 0.031467$ \\
\hline 4 & S4 & 2001.082 & $2.387950777 \pm 0.035855$ \\
\hline 5 & S5 & 4256.355 & $5.079235843 \pm 0.137827$ \\
\hline 6 & S6 & 2199.387 & $2.624594548 \pm 0.011649$ \\
\hline 7 & S7 & 3254.612 & $3.883826249 \pm 0.050986$ \\
\hline 8 & S8 & 1552.19 & $1.852275333 \pm 0.021549$ \\
\hline 9 & S9 & 2602.007 & $3.105053113 \pm 0.040624$ \\
\hline 10 & S10 & 1355.688 & $1.617782869 \pm 0.04342$ \\
\hline
\end{tabular}


Table(3) Uranium concentrations in soil samples of Al-Najaf holy city

\begin{tabular}{|c|c|c|c|}
\hline No. & Location sample & $\begin{array}{c}\text { Track density } \\
(\text { Track.mm-2) }\end{array}$ & $\begin{array}{c}\text { Uranium concentration } \\
(\mathrm{ppm})\end{array}$ \\
\hline 1 & S1 & 1276.967 & $0.142433 \pm 0.008378$ \\
\hline 2 & S2 & 1414.578 & $0.157782 \pm 0.016757$ \\
\hline 3 & S3 & 1577.429 & $0.175947 \pm 0.01726$ \\
\hline 4 & S4 & 1352.082 & $0.150811 \pm 0.015081$ \\
\hline 5 & S5 & 1114.206 & $0.124279 \pm 0.01307$ \\
\hline 6 & S6 & 1414.669 & $0.157792 \pm 0.016924$ \\
\hline 7 & S7 & 1164.293 & $0.129865 \pm 0.014746$ \\
\hline 8 & S8 & 1652.545 & $0.184325 \pm 0.017511$ \\
\hline 9 & S9 & 1452.136 & $0.161971 \pm 0.015567$ \\
\hline 10 & S10 & 838.7867 & $0.093558 \pm 0.000938$ \\
\hline
\end{tabular}

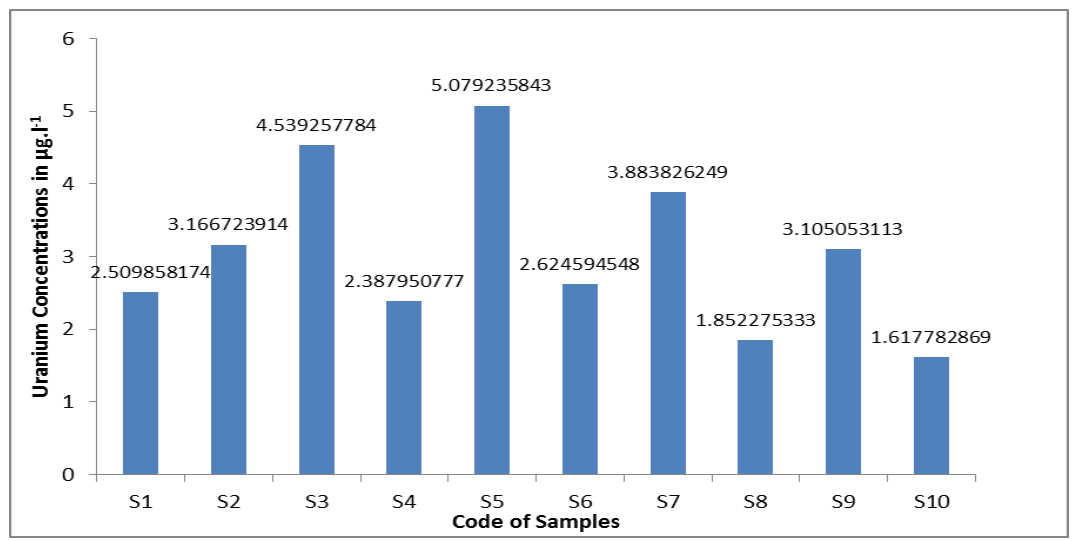

Figure (5) the Uranium concentrations in Groundwater samples

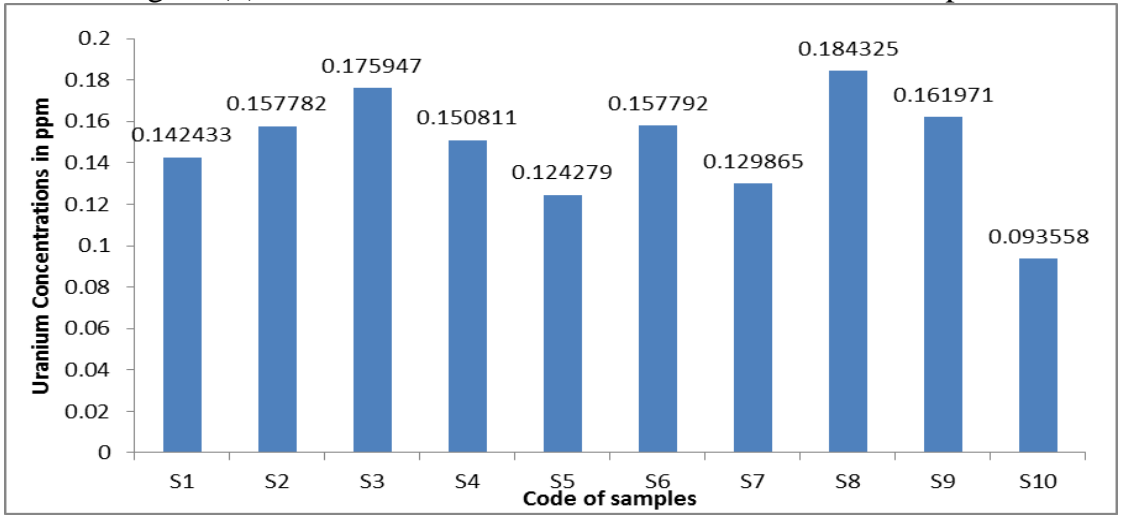

Figure (6) the Uranium concentrations in Soil samples

\section{Conclusion:}

From the results obtained in the present research. All results obtained in groundwater are less than the allowed limits by WHO while the results of uranium in soil are less than the allowed limits by UNSCEAR .

\section{Acknowledgment:}

I would like to knowledge all those contributed in declaring this issue. Special thanks to the staff of the department of physics at Kufa university.

\section{References :}

[1] Bochicchio.F., McLaughling, J.P.and Piermattei. S., " Radon in indoor air", European Collaborative Action(Report No 15),pp50, (1995).

[2] . Todorov, P. and Ilieva, E. N.," Contamination with uranium from natural and anthropological sources", Rom. Journ. Phys.,51(1-2) : 27-34, (2006).

[3] D. C.Hoffman, F. O. Lawrence, J. L. Mewherter, F. M. Rourke, "Detection of Plutonium-244 in Nature". Nature234 (5325): $132-$ 134, (1971).

[4] N.H. Kadhim, R. Y. Kassim and S. J. Jabbar, " Estimation the Radioactive Pollution by Uranium in the Soil of Al-Kut City/ Iraq ", Baghdad Science Journal Vol.8,(2), 532-537, (2011). 
[5] N.H. Kadhim, R. Y. Kassim and A. M. Alwan, " Uranium concentrations in the Soil of Al-Kut City/ Iraq ", Al-Nahran Science Journal Vol.15,(2), 1-5, (2012).

[6] A K. Brindha - L. Elango, " Occurrence of uranium in groundwater of a shallow granitic aquifer and its suitability for domestic use in southern India", J Radioanal Nucl Chem (2013) 295:357-367. [7] Cooperation with the Local Government, "Development Strategy for the Holy Province of Najaf," Holy Najaf Province Council, report (2008).

[8] S.Yaekoop, "Water of Al.Najaf in last horns", 2(101), (1937). (Arabic language).

[9] Nidhala H. K., Ryadh Y. K.and Shurouq J. J.," Estimation the Radioactive Pollution by Uranium in the Soil of Al-Kut City/ Iraq", Baghdad Science Journal Vol.8(2), (2011).

[10] Al-Baidhani, M. A., 2006" Determination of the Radioactivity in Soil and Water in Baghdad, Karbala and Basrah Samples", M.Sc. Thesis, Al-Nahrain University, College of Science.

[11] United Nations Scientific Committee on the Effects of Atomic Radiation, UNSCEAR,1993 "Sources, Effect, and Risks of Ionizing Radiation", Report to the general Assembly with Scientific Annexes, United Nations

[12] WHO (World Health Organization), Guidelines for drinking-water quality (3rd ed.).( 2004). 